\title{
Effect of the nitric oxide donor, glyceryl trinitrate, on human gall bladder motility
}

\author{
R Greaves, J Miller, L O’Donnell, A McLean, M J G Farthing
}

\begin{abstract}
Background-Nitric oxide is a major neurotransmitter in non-adrenergic, noncholinergic (NANC) pathways. NANC inhibitory innervation has been shown in human gall bladder muscle in vitro; the role of nitric oxide in human gall bladder emptying however is undefined.

Aims-To study the effect of glyceryl trinitrate, a nitric oxide donor, on gall bladder emptying in healthy subjects using a randomised, double blind, crossover, placebo controlled design.

Methods-Ultrasonographic gall bladder volume was measured in the fasting state in eight healthy volunteers after randomised administration of either glyceryl trinitrate $1200 \mu \mathrm{g}$ buccal spray or placebo spray. On two further occasions, after randomised administration of either glyceryl trinitrate $1200 \mu \mathrm{g}$ buccal spray or placebo spray, gall bladder volumes were also measured after a liquid test meal.

Results-Glyceryl trinitrate significantly increased fasting gall bladder volume to a mean of $114 \%$ (SEM 5\%) of pretreatment volume $(p=0.039)$. Glyceryl trinitrate also significantly impaired gall bladder emptying between five and $\mathbf{4 0}$ minutes postprandially. Gall bladder ejection fraction was also reduced after glyceryl trinitrate compared with placebo $(43(6.9) \%$ versus 68.4 (6.5)\%, $\mathrm{p}=0.016)$.

Conclusions-This study shows that glyceryl trinitrate produces gall bladder dilatation in the fasting state and reduces postprandial gall bladder emptying, suggesting that nitric oxide mechanisms may be operative in the human gall bladder in vivo.

(Gut 1998;42:410-413)
\end{abstract}

Keywords: gall bladder motility; nitric oxide; glyceryl trinitrate

M J G Farthing

Department of

Radiology, St

Bartholomew's

Hospital, London

J Miller

A McLean

Department of Medicine, Mayo

General Hospital,

Castlebar, Ireland

L O’Donnell

Correspondence to:

Dr Greaves.

Accepted for publication 1 October 1997

Nitric oxide (NO) was initially identified as an endothelium derived relaxing factor in $1987,{ }^{1}$ and since then it has been shown to have a wide variety of biological functions. In the cardiovascular system NO plays an important physiological role in controlling vascular tone. Inhibition of NO synthase, the enzyme responsible for NO production from L-arginine, causes marked vasoconstriction in the human vasculature, suggesting that there is a physiological, NO dependent vasodilator tone that is important in regulating blood flow. ${ }^{2}$ Nitrovasodilators such as glyceryl trinitrate (GTN), which has been used in the treatment of angina for over a century, act after metabolism to $\mathrm{NO}$ in the vasculature, with subsequent vascular smooth muscle relaxation. ${ }^{3}$

In addition to its role in the cardiovascular system, NO is a neurotransmitter both in the central and enteric nervous system. ${ }^{4-7}$ In the human gall bladder NADPH diaphorase staining neurones (NO producing neurones) have been characterised, ${ }^{8}$ and in vitro electrical activation of non-adrenergic, non-cholinergic (NANC) neurones produces gall bladder relaxation. ${ }^{9}$ Inhibition of $\mathrm{NO}$ synthase in guinea pig gall bladder in vivo increases basal gall bladder pressure, indicating that there is a continuous "tick-over" production of $\mathrm{NO}$ in the gall bladder which contributes to the maintenance of gall bladder volume in the fasting state.$^{10}$ However, the effects of NO on human gall bladder motility have not been reported.

The aim of the present study was to examine the effect of the NO donor GTN on human gall bladder volume and emptying in healthy volunteers.

\section{Methods}

SUBJECTS

Eight healthy subjects (five females) volunteered to participate in the study. The subjects were free from any gastrointestinal symptoms and gave no history of previous gastric surgery or diabetes mellitus. They were on no medication throughout the study period. All subjects had normal gall bladders on ultrasonography. The median values for age, weight, and height were: 33 years (range 28-35), $67 \mathrm{~kg}$ (range 54-74), and $1.73 \mathrm{~m}$ (range 1.61-1.83). The median body mass index of the subjects was $21.8 \mathrm{~kg} / \mathrm{m}^{2}$ (range 20.2-24.1). Each subject gave written informed consent. Ethical approval was obtained from the East London and City Health Authority Research Ethics Committee.

\section{STUDY DESIGN} the response of fasting gall bladder volume to GTN and placebo was compared. In the second, the effects of GTN and placebo on postprandial gall bladder emptying after a standard liquid meal were compared.

In the fasting volume study, subjects were randomly assigned to receive GTN buccal spray (Nitrolingual, Merck-Lipha Pharmaceuticals, Middlesex, UK) $1200 \mu \mathrm{g}$ and, on a separate day, an identical tasting placebo spray (Merck-Lipha Pharmaceuticals). Fasting gall bladder volume was measured after an eight hour fast, following which GTN or placebo 


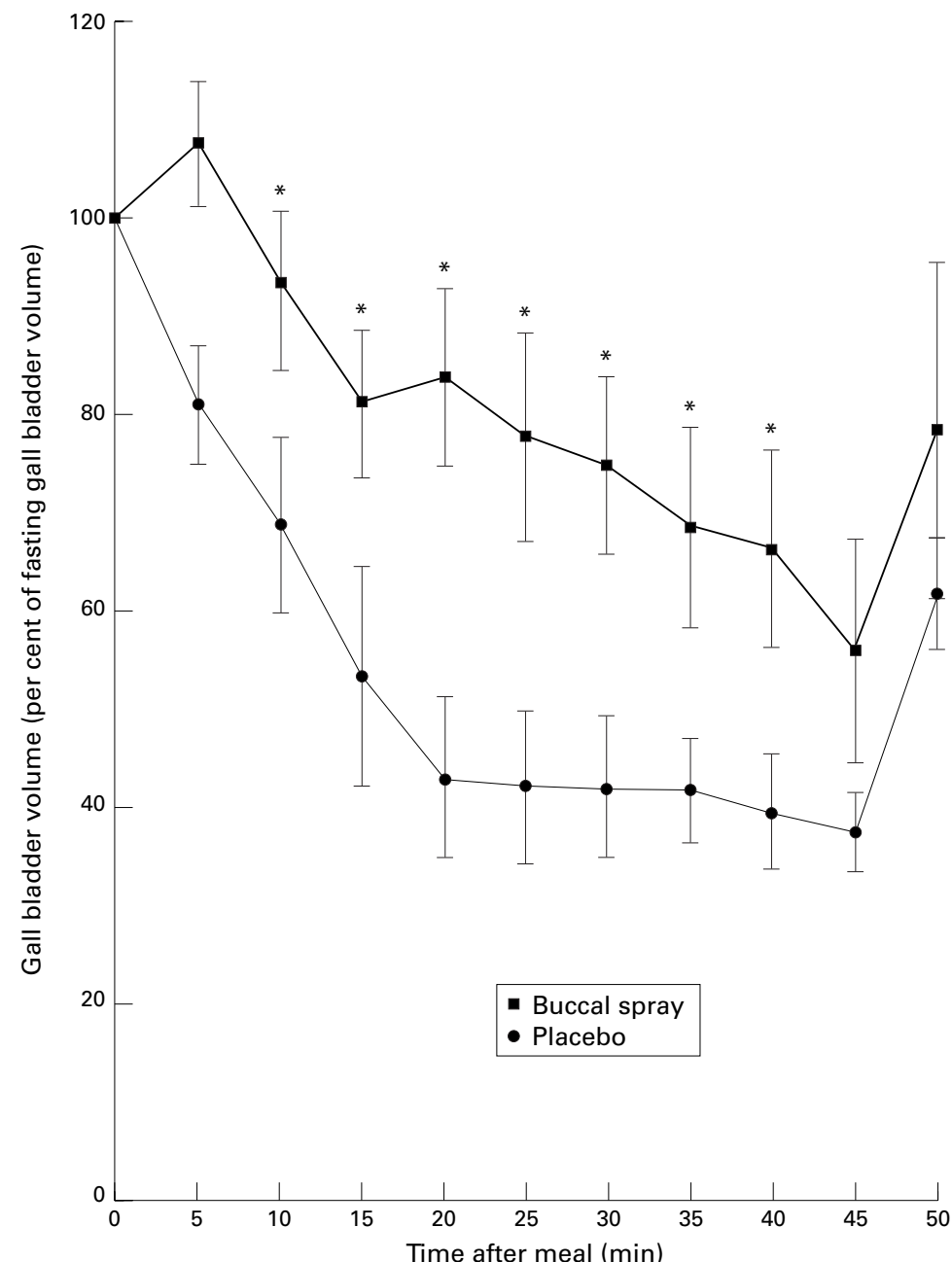

Figure 1 Effect of GTN $1200 \mu \mathrm{g}$ buccal spray or placebo on the time course of gall bladder emptying following a liquid test meal in healthy subjects, expressed as percentage of control fasting volume. Results are expressed as mean (SEM). ${ }^{\star} p<0.05$.

spray was given, and gall bladder volume was measured every five minutes for 15 minutes.

For the postprandial experiment, the effect of GTN and placebo on gall bladder emptying was measured after consumption of a $250 \mathrm{ml}$ liquid test meal $(1.050 \mathrm{MJ} ; 14 \%$ protein, $37 \%$ corn oil, 54\% carbohydrate; "Ensure", Abbott Laboratories, Kent, UK). Fasting gall bladder volume was measured after an eight hour fast and the liquid test meal was immediately ingested within two minutes under supervision. The subjects then randomly received either GTN spray $1200 \mu \mathrm{g}$ or placebo; the alternate spray was given on a separate day. Gall bladder volume was measured every five minutes for 50 minutes, or until the gall bladder began to refill.

Table 1 Effect of glyeryl trinitrate (GTN) on fasting gall bladder volume

\begin{tabular}{lll}
\hline & \multicolumn{2}{l}{ Volume $(\mathrm{ml})$} \\
\cline { 2 - 3 } Time (min) & Placebo & GTN \\
\hline 0 & $100(0)$ & $100(0)$ \\
5 & $96.4(5.1)$ & $105.9(4.7)$ \\
10 & $98.0(5.0)$ & $114.4(5.0)^{\star}$ \\
15 & $98.9(2.5)$ & $111.7(5.2)$ \\
\hline
\end{tabular}

Results are expressed as mean (SEM).

${ }^{\star} \mathrm{p}=0.039$ (Wilcoxon signed rank test) $v$ volume at time $0 \mathrm{~min}$.

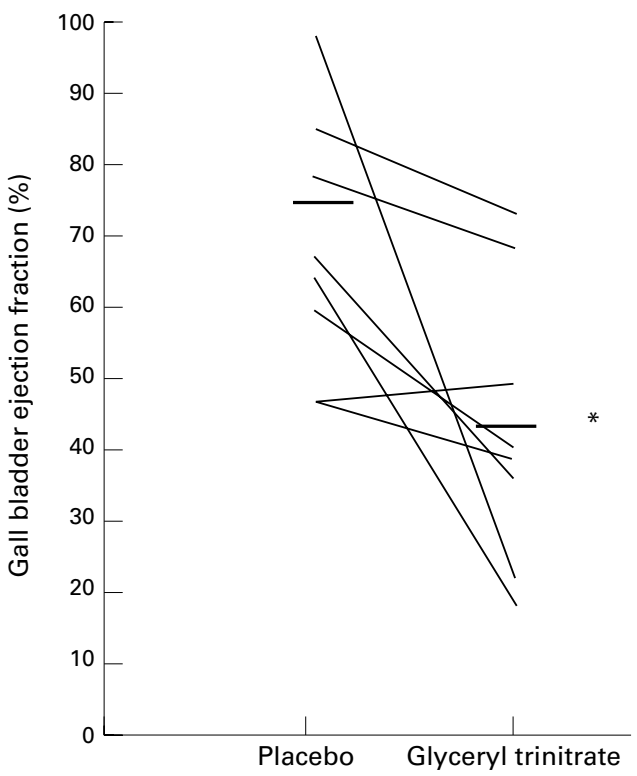

Figure 2 Gall bladder ejection fraction following a liquid test meal with either GTN $1200 \mu \mathrm{g}$ or placebo. The solid horizontal bars represent the mean values. ${ }^{\star} p<0.05$.

GALL BLADDER EMPTYING

Gall bladder emptying was assessed by serial measurement of gall bladder volume using ultrasound. Studies were conducted by a radiologist using a $3.5 \mathrm{MHz}$ transducer (Accuson $128 X P$ ). The radiologist was unaware of which treatment the volunteer had received. After an eight hour fast the gall bladder was scanned in the right anterior oblique position. At each time point, two separate gall bladder measurements of length, width, and height were obtained in the longitudinal and transverse planes and the mean of these measurements was used for calculation of the gall bladder volume. Gall bladder volume was determined using the ellipsoid method $^{11}$ as we have previously used $^{12}$ :

$$
\mathrm{V}=(\mathrm{L} \times \mathrm{W} \times \mathrm{H}) \times \pi / 6
$$

where $\mathrm{V}$ is the gall bladder volume, $\mathrm{L}$ is the gall bladder length (sagitally), $\mathrm{W}$ is the width, and $\mathrm{H}$ is the height of the gall bladder (axially).

The gall bladder ejection fraction was calculated according to the formula:

$$
\mathrm{EF}=\frac{\mathrm{V}_{\mathrm{p}}=\mathrm{V}_{\min }}{\mathrm{V}_{\mathrm{p}}} \times 100 \%
$$

where $\mathrm{EF}$ is ejection fraction, $\mathrm{V}_{\mathrm{p}}$ is fasting gall bladder volume, and $\mathrm{V}_{\min }$ is the minimal gall bladder volume.

\section{STATISTICAL METHODS}

Non-parametric paired data were analysed using the Wilcoxon signed rank test. Values of p $<0.05$ were considered significant. Results shown are mean (SEM) values.

\section{Results}

EFFECT OF GTN ON FASTING GALL BLADDER VOLUME

Mean fasting gall bladder volumes prior to GTN or placebo administration were similar: (20.1 (1.5) $\mathrm{ml}$ versus 25.1 (3.2) $\mathrm{ml}$, NS). The placebo spray had no significant effect on gall 
bladder volume over 15 minutes (table 1). GTN spray, however, produced dilatation of the gall bladder which was maximal at $10 \mathrm{~min}-$ utes in $6 / 8$ subjects. The mean increase was to 114 (5)\% of fasting volume at 10 minutes $(\mathrm{p}=0.039)$.

EFFECT OF GTN ON POSTPRANDIAL GALL BLADDER EMPTYING

There was no significant difference between fasting gall bladder volume prior to GTN or placebo spray (21.3 (2.4) ml versus 19.9 (1.8) $\mathrm{ml})$. Gall bladder emptying was significantly impaired after GTN administration compared with placebo at five minutes, and this effect persisted until 40 minutes (fig 1). Ejection fraction was also reduced with GTN compared with placebo (43.2 (7)\% versus $68.4(6.5) \%$, $\mathrm{p}=0.016$ ) (fig 2).

\section{Discussion}

This study shows that in healthy humans a standard dose of buccal GTN spray produces dilatation of the gall bladder in the fasting state and impairs postprandial gall bladder emptying. In the cardiovascular system, GTN exerts its biological effect through the donation of NO, with consequent arterial smooth muscle relaxation. ${ }^{3}$ It is also likely that NO donation by GTN with consequent gall bladder smooth muscle relaxation is the mechanism underlying the effect of this drug on gall bladder volume. Nitric oxide containing neurones have been visualised using immunohistochemical methods in both the guinea pig and human gall bladder. $^{8}$ In guinea pig studies in vivo, inhibition of NO synthase increases both resting tone and cholecystokinin (CCK) induced contraction. Moreover, NO donation in the form of sodium nitroprusside reduced the response of guinea pig gall bladder in vitro to CCK by about $80 \% .{ }^{10}$ Our data provide evidence that NO pathways may be operative in the human gall bladder in vivo. However, the coordinated delivery of bile into the duodenum also requires a complex interplay between gall bladder contraction, cystic duct resistance, and spincter of Oddi relaxation. ${ }^{13}{ }^{14}$ In guinea pigs and rabbits, the sphincter of Oddi produces NO synthase, which acts locally to reduce sphincter tone. ${ }^{15}$ Ambulatory sphincter of Oddi manometric studies were not attempted in this study, as they are invasive and technically demanding.

Apart from a direct effect on gall bladder smooth muscle and sphincter of Oddi, NO may also indirectly reduce postprandial gall bladder emptying by reducing gastric emptying, and hence the rate of nutrient delivery to the duodenum, ${ }^{4}$ with consequent reduction of nutrient release of CCK and gall bladder contraction. However, as GTN affects fasting gall bladder volume in vivo, it is likely that this effect on the gall bladder is independent, at least in part, of gastric emptying.

The impairment of gall bladder emptying by buccal GTN may have implications for gallstone pathogenesis in subjects on other nitrate formulations. Gallstones arise because of a triple defect in the hepatobiliary system: cholesterol supersaturation of gall bladder bile, ${ }^{16}$ reduced gall bladder emptying, ${ }^{17}$ and an increased rate of cholesterol crystal nucleation, owing to the presence of biliary nucleating factors. $^{18}$ In animal studies, reduced gall bladder emptying precedes gallstone synthesis. ${ }^{19}$ In humans, impaired gall bladder emptying is associated with gallstone formation ${ }^{20}{ }^{21}$; the rate of gallstone formation may therefore be accelerated in patients on long term nitrates.

The relaxant effect of GTN on the gall bladder might have therapeutic possibilities. Hassel reported three patients with biliary colic whose pain responded rapidly to a variety of nitrate formulations (buccal GTN $400 \mu \mathrm{g}$, sublingual GTN $500 \mu \mathrm{g}$, isosorbide dinitrate $20 \mathrm{mg}$ ). He suggested that GTN might be a useful adjunct to standard analgesia in acute biliary colic. ${ }^{22}$

This study used a pharmacological dose of GTN as an NO donor, and it therefore does not show definitively that NO plays a physiological role in human gall bladder motility. To determine whether NO has a physiological role would require parenteral NO synthase inhibition, but this was considered hazardous and unethical, particularly with regard to the risk of mesenteric small vessel ischaemia. ${ }^{23}$

In conclusion, this study is the first to show a significant impairment of gall bladder emptying with buccal GTN compared with placebo in healthy human subjects. This implies that NO mechanisms may be operative in the human gall bladder, and may have implications for gallstone formation in subjects on long term nitrates.

Grant support was provided by the Frances and Augustus Newman Foundation and the Health Research Board (Ireland). This work was presented in part at the British Society of Gastroenterology (Gut 1996;38(suppl 1):A63) and at Digestive Diseases Week (Gastroenterology 1996;110:A670).

1 Palmer RM, Ferrige AG, Moncada S. Nitric oxide release accounts for the biological activity of endothelium-derived relaxing factor. Nature 1987;327:524-6.

2 Vallance P, Collier J, Moncada S. Effects of endotheliumderived nitric oxide on peripheral arteriolar tone in man. derived nitric oxide on perip
Lancet 1989;ii:997-1000.

3 Feelisch M, Kelm M. Biotransformation of organic nitrates to nitric oxide by vascular smooth muscle and endothelia cells. Biochem Biophys Res Commun 1991;180:286-93.

4 Desai KM, Sessa WC, Vane JR. Involvement of nitric oxide in the reflex relaxation of the stomach to accommodate food or fluid. Nature 1991;351:477-9.

5 Knowles RG, Palacios M, Palmer RM, Moncada S. Formation of nitric oxide from L-arginine in the central nervous system: a transduction mechanism for stimulation of the soluble guanylate cyclase. Proc Natl Acad Sci USA 1989;86: 5159-62.

6 Burleigh DE. Ng-nitro-L-arginine reduces nonadrenergic, noncholinergic relaxations of human gut. Gastroenterology 1992;102:679-83.

7 Mearin F, Mourelle M, Guarner F, et al. Patients with achaMearin F, Mourelle M, Guarner F, et al. Patients with acha-
lasia lack nitric oxide synthase in the gastro-oesophageal

junction. Eur f Clin Invest 1993;23:724-8.
8 Talmage EK, Mawe GM. NADPH-diaphorase and VIP are Talmage EK, Mawe GM. NADPH-diaphorase and VIP are
co-localized in neurons of gall bladder ganglia. $\mathcal{f}$ Auton Nerv Syst 1993;43:83-9.

9 McKirdy ML, McKirdy HC, Johnson CD. Non-adrenergic non-cholinergic inhibitory innervation shown by electrical field stimulation of isolated strips of human gall bladder muscle. Gut 1994;35:412-16.

10 Mourelle M, Guarner F, Molero X, Moncada S, Malagelada JR. Regulation of gall bladder motility by the argininenitric oxide pathway in guinea pigs. Gut 1993;34:911-15.

11 Dodds WJ, Groh WJ, Darweesh RM, Lawson TL, Kishk SM, Kern MK. Sonographic measurement of gall bladder volume. AfR Am f Roentgenol 1985;145:1009-11.

12 O'Donnell LJ, Wilson P, Guest P, et al. Indomethacin and O'Donnell LJ, Wilson P, Guest P, et al. Indomethacin and
postprandial gall bladder emptying. Lancet 1992;339:26971 .

13 Dodds WJ, Hogan WJ, Geene JE. Motility of the biliary system. In: Scultz SG, Wood JD, Rauner BB, eds. Handbook of 
physiology. Section 6, The gastrointestinal system. New York: Oxford University Press, 1989:1055-61.

14 Behar J, Biancini P. Pharmacology of the biliary tract. In: Scultz SG, Wood JD, Rauner BB, eds. Handbook of physiology. Section 6, The gastrointestinal system. New York: Oxford University Press, 1989:1103-30.

15 Mourelle M, Guarner F, Moncada S, Malegelada JR. The arginine/nitric oxide pathway modulates sphincter of Oddi motor activity in guinea pigs and rabbits. Gastroenterology 1993;105:1299-305.

16 Admirand WH, Small DM. The physicochemical basis of cholesterol gallstone formation in man. 7 Clin Invest 1968; 47:1043-52.

17 Fisher RS, Stelzer F, Rock E, Malmud LS. Abnormal gall bladder emptying in patients with gallstones. Dig Dis Sci 1982;27:1019-24.

18 Holan KR, Holzbach RT, Hermann RE, Cooperman AM, Claffey WJ. Nucleation time: a key factor in the pathogen- esis of cholesterol gallstone disease. Gastroenterology 1979;77:611-7.

9 Doty JE, Pitt HA, Kuchenbecker SL, DenBesten L. Impaired gall bladder emptying before gallstone formation in the prairie dog. Gastroenterology 1983;85:168-74.

20 Forgacs IC, Maisey MN, Murphy GM, Dowling RH. Influence of gallstones and ursodeoxycholic acid therapy on gall bladder emptying. Gastroenterology 1984;87:299307 .

21 Pomeranz IS, Shaffer EA. Abnormal gall bladder emptying in a subgroup of patients with gallstones. Gastroenterology 1985;88:787-91.

22 Hassel B. Treatment of biliary colic with nitroglycerin. Lancet 1993;342:1305.

23 Mourad FH, O'Donnell LJD, Andre EA, et al. L-arginine, nitric oxide, and intestinal secretion: studies in rat jejunum in vivo. Gut 1996;39:539-44. 